\title{
Ceratoplastia lamelar em cães utilizando membrana fetal eqüina como enxerto. Estudo experimental
}

\author{
Lamelar keratoplasty in dogs using equine fetal membrane as graft. Experimental study
}

\author{
Cintia Aparecida Lopes Godoy ${ }^{1}$ \\ José Luiz Guerra² \\ Paulo Sergio de Moraes Barros ${ }^{3}$
}

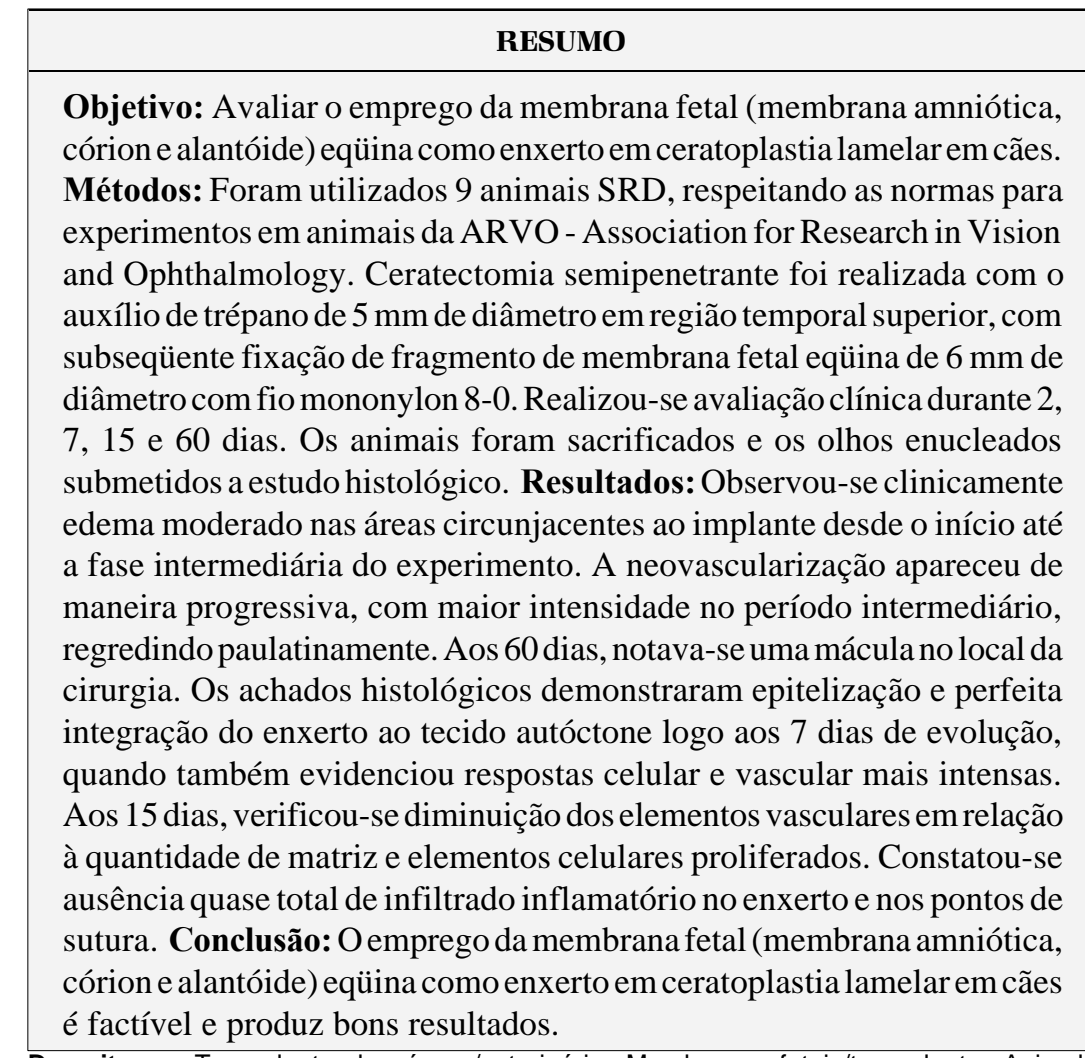

Descritores: Transplante de córnea/veterinária; Membranas fetais/transplante; Animal; Cães/cirurgia; Cavalos/cirurgia
${ }^{1}$ Pós-graduanda do Curso de Cirurgia da Faculdade de Medicina Veterinária e Zootecnia da Universidade de São Paulo - USP/ bolsista do CNPq.

${ }^{2}$ Professor Doutor do Departamento de Patologia da Faculdade de Medicina Veterinária e Zootecnia da Universidade de São Paulo - USP

${ }^{3}$ Professor Titular do Departamento de Cirurgia da Faculdade de Medicina Veterinária e Zootecnia da Universidade de São Paulo - USP.

Endereco para correspondência: Cintia Aparecida Lopes Godoy - R. Manoel Pita, 138 - São Paulo (SP) CEP 02478-000 - FAX (11) 3091-7667.

E-mail: cintiagodoy@ig.com.br

Recebido para publicação em 08.08.2001 Aceito para publicação em 04.03.2002

Nota editorial: Pela análise deste trabalho e por sua anuência na divulgação desta nota, agradecemos à Dra. Ana Luisa Höfling de Lima Farah.

\section{INTRODUÇÃO}

A reconstituição da superfície ocular tem sido desafio em oftalmologia.

A ceratoplastia (lamelar ou penetrante) é um dos métodos cirúrgicos mais utilizados para a reconstrução da córnea. Apesar de a córnea ser o material ideal para o transplante, sua disponibilidade não é vasta, por isso a investigação de novos materiais que sirvam como substitutos na reconstrução da superfície ocular tem sido extensa.

Neste contexto, a utilização de membranas biológicas tem ganhado ênfase na última década. Em oftalmologia veterinária, pericárdio ${ }^{(1-4)}$, peritônio ${ }^{(5)}$, cápsula renal ${ }^{(6)}$, túnica vaginal ${ }^{(7)}$, submucosa de intestino delgado ${ }^{(8-9)}$ e escama de sardinha ${ }^{(10)}$ foram investigados experimentalmente como enxertos em córnea de cão.

Atualmente, a membrana amniótica é o alvo mais freqüente dos pesquisadores na área das cirurgias reconstrutivas da superfície ocular ${ }^{(11-24)}$. Há 
também relatos de sua utilização em cirurgias de glaucoma ${ }^{(25-26)}$ e para a redução de "haze" em córnea de coelhos submetidos a fotoablação com "excimer laser" (PRK) ${ }^{(27)}$, além da tentativa de utilizá-la como substrato para o cultivo de células do limbo a serem transplantadas para a superfície corneana ${ }^{(28)}$.

Em 1998, relataram-se bons resultados com a utilização de membrana amniótica eqüina em ceratoplastia profunda em cães $^{(29)}$, o que foi fundamental para a realização deste estudo, cujo objetivo foi avaliar a aplicabilidade da membrana fetal eqüina preservada em glicerina $98 \%$ como enxerto em ceratoplastia lamelar em cães.

\section{MÉTODOS}

A membrana fetal foi colhida de égua clinicamente sadia, logo após a ocorrência do parto em 1994. Em seguida, foi lavada com água corrente e com solução fisiológica na seqüência. Para sua preservação, foi imersa em solução de glicerina a 98\%, na qual permaneceu até o momento de sua utilização.

O uso dos animais foi de acordo com as normas da ARVO para a utilização de animais em pesquisa.

Nove cães SRD, adultos, com peso médio de $10 \mathrm{~kg}$ foram divididos em 3 grupos de 2 animais cada e 1 grupo de 3 animais. Os animais, após adequadamente anestesiados (préanestesia - Acepromazina - 0,05 - 0,2 mg/kg; indução - Thiopental: $12,5 \mathrm{mg} / \mathrm{kg}$; anestesia inalatória - Halotano) foram submetidos à ceratectomia semipenetrante com o auxílio de trépano de $5 \mathrm{~mm}$ de diâmetro, em quadrante temporal superior, onde foi suturado fragmento de $6 \mathrm{~mm}$ de diâmetro, previamente hidratado, da membrana fetal, com sutura simples separada com mononylon 8-0.

Os cães foram mantidos em canis individuais e com colar protetor elizabetano. Optou-se pela não utilização de colírios ou pomadas oftálmicas contendo antibióticos, apenas a limpeza com solução fisiológica, o que possibilitou a avaliação da possível função antibiótica da porção amniótica da membrana fetal. Se, durante a evolução do experimento, ocorressem episódios de infecção que exigissem a utilização de antibióticos, estes teriam sido utilizados, para não submeter o animal a desconfortos desnecessários. Contudo, não houve a necessidade.

As avaliações clínicas foram diárias, com luz direcionada e magnificação, durante 2, 7, 15 e 60 dias. Ao final destes períodos, os animais foram sacrificados, realizando-se anestesia profunda com a aplicação de Thiopental na dose $25 \mathrm{mg} / \mathrm{kg}$ seguida de injeção intravenosa de cloreto de potássio para indução de parada cardiorrespiratória. Os olhos enucleados foram fixados em formol a $10 \%$. Cortes de $0,5 \mathrm{~cm}$ de largura foram feitos ao longo do diâmetro do tecido implantado e da esclera vizinha a esse tecido e incluído em parafina. Cortes de $0,5 \mu \mathrm{m}$ foram corados por hematoxilina-eosina, de acordo com rotina clássica para esse tipo de procedimento ${ }^{(30)}$.

\section{RESULTADOS}

Todas as alterações observadas foram compatíveis com as habitualmente vistas no pós-operatório de ceratoplastias.

Os animais apresentaram maior grau de fotofobia/blefarospasmo nos períodos iniciais, bem como a hiperemia. A quantidade de secreção foi variável entre os animais; sua qualidade pode ser classificada como mucosa na maior parte dos grupos, sendo raro o aparecimento de componente purulento. Edema foi observado somente nas áreas circunjacentes ao enxerto, não interferindo com a transparência da córnea nas áreas distantes, principalmente nos períodos iniciais (Figura 1). A vascularização da área do implante apareceu a partir dos 7 dias na maioria dos animais, com maior intensidade no $17^{\circ} / 18^{\circ} \mathrm{dia}$, quando inicia sua regressão. Aos 60 dias, apenas um dos animais apresentou vascularização discreta relacionada com a presença de 3 pontos de sutura (Figura 2). Todos apresentavam uma mácula neste local ao final do experimento.

Os achados histológicos demostraram infiltrado inflamatório discreto de polimorfonucleares neutrófilos no estroma subjacente à membrana fetal, aos 2 dias. Aos 7 dias, o tecido implantado encontrava-se perfeitamente integrado ao tecido autóctone, com sua epitelização em toda extensão, com epitélio plano estratificado; notou-se proliferação de fibroblastos sobre o substrato (membrana fetal) (Figura 3) e, na periferia do implante, resposta celular e vascular mais intensas. Aos 15 dias, verificou-se aumento dos elementos matriciais amorfos, com diminuição dos vasos neoformados. Fato relevante diz respeito à ausência quase total de infiltrado inflamatório. Essas mesmas observações são válidas aos pontos de sutura, onde não se observou, em nenhuma oportunidade, resposta indesejável como formação de granuloma tipo corpo estranho. Aos 60 dias, observou-se epitelização completa da área do

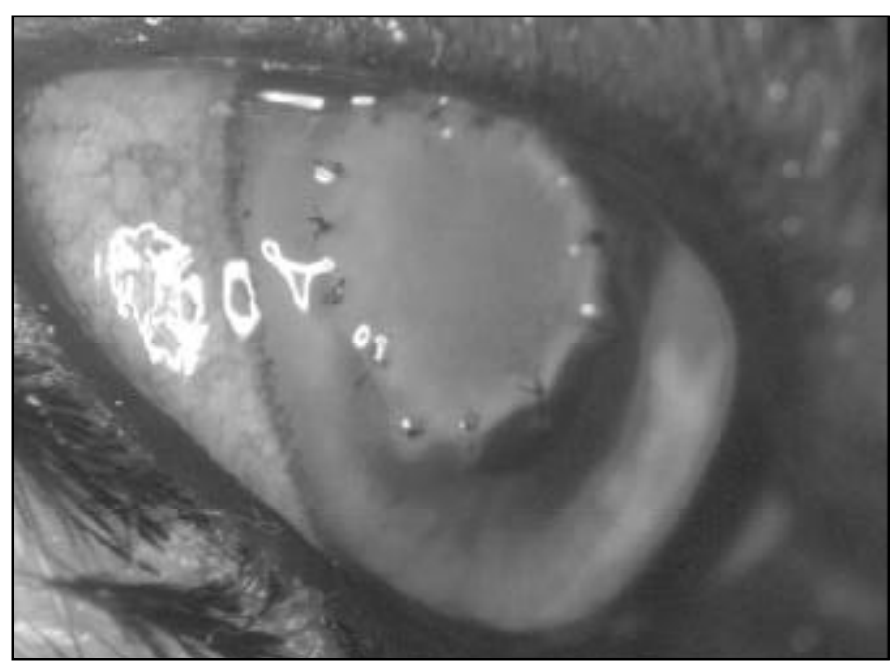

Figura 1 - Fotografia correspondente ao período de 2 dias de pósoperatório. Observa-se perfeita aposição da membrana fetal ao leito corneano, com aumento de sua opacidade, em relação ao período anterior, bem como a hiperemia da conjuntiva bulbar. Nota-se o início da invasão dos neovasos a partir do limbo na região temporal 
implante, com formação de epitélio pavimentoso estratificado e, na região subjacente, a presença de colágeno modelado com pouca celularidade (Figura 4).

\section{DISCUSSÃO}

Em 1910, houve o primeiro relato do emprego de membranas fetais para enxertos de pele ${ }^{(31)}$. No olho, a membrana amniótica foi utilizada pela primeira vez em 1940, na reparação de simbléfaro e defeitos conjuntivais ${ }^{(32)}$, passando por um período obscuro nas décadas seguintes, até que, em 1995, foram publicados os resultados da utilização da membrana amniótica em córnea de coelhos severamente danificadas ${ }^{(11)}$. Atualmente, é vasta a publicação concernente a este assunto ${ }^{(11-29,33-41)}$, destacando diversas propriedades da membrana

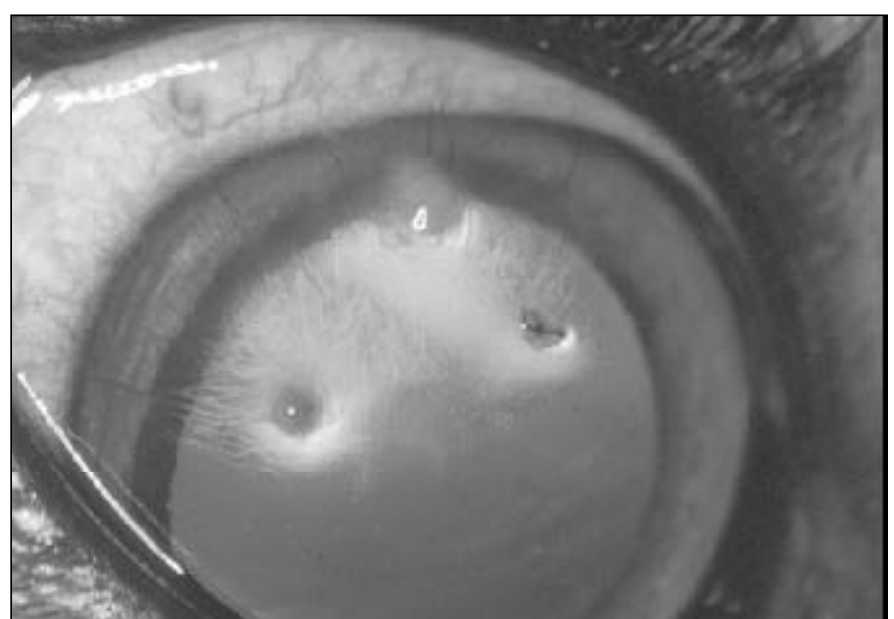

Figura 2 - Fotografia correspondente aos 60 dias de evolução. Observa-se a permanência de 3 pontos de sutura, com vasos encaminhando-se para os mesmos. Notam-se vasos fantasmas. A área do enxerto apresenta-se como uma mácula localizada fora do eixo visual

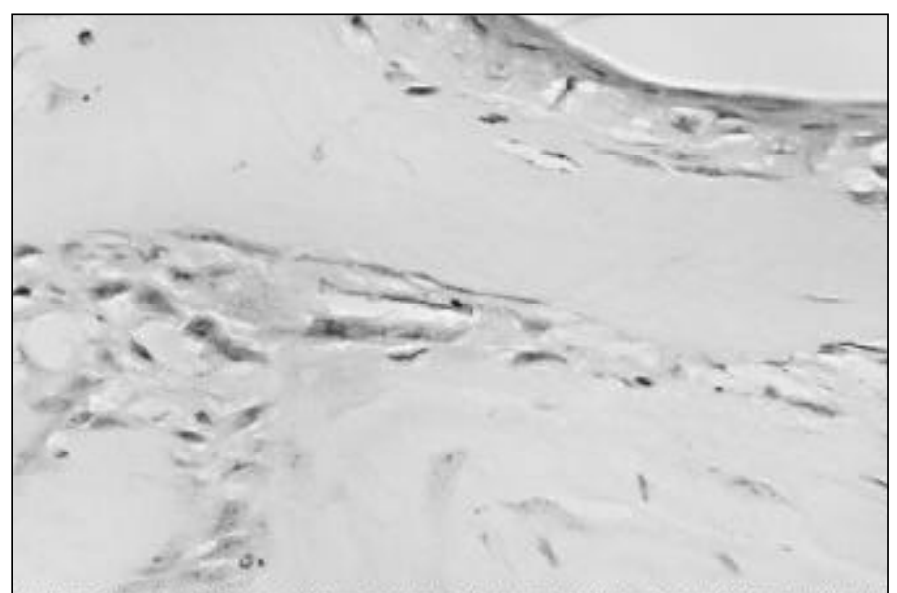

Figura 3 - Fotomicrografia de corte histológico da área de implante com 7 dias de evolução, evidenciando o tecido implantado, com regeneração epitelial, além da presença de inúmeras células fusiformes. Coloração: HE. Aumento $140 X$

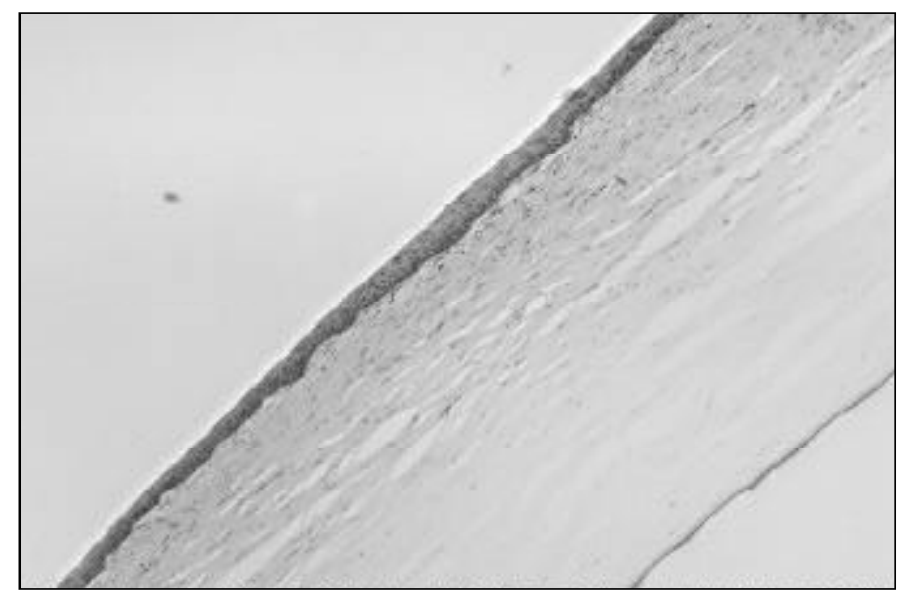

Figura 4 - Fotomicrografia de corte histológico da área de implante, delimitada pela regiấo esclero-corneana, com 60 dias de evolução, mostrando tecido implantado revestido por epitélio pavimentoso estratificado não queratinizado. Nota-se o tecido implantado com escassez de células e abundante quantidade de matriz, estando, portanto, colagenizado. Coloração: HE. Aumento: $34 \mathrm{X}$

amniótica que a tornam bom material para o tratamento de diversas oftalmopatias.

No presente estudo, as avaliações clínicas demonstraram os mesmos fenômenos já observados por outros autores que realizaram procedimentos semelhantes com a implantação das mais variadas membranas ${ }^{(1-7,10,29)}$.

A fotofobia/blefarospasmo pode ser considerada decorrente do trauma cirúrgico com exposição das fibras nervo$\operatorname{sas}^{(42)}$ e da presença do fio de sutura sem o sepultamento dos nós ${ }^{(43)}$. A secreção mucosa constante ocorreu por estímulo das células caliciformes conjuntivais. A remissão espontânea dos raros episódios de secreção purulenta foi resultado dos mecanismos de defesa da própria córnea ${ }^{(43)}$ como também da possível propriedade antimicrobiana atribuída à membrana amniótica ${ }^{(39)}$. O edema de córnea, observado como uma opacidade circunjacente à área do implante, é esperado, pois com a ceratectomia provoca-se a quebra da integridade da camada epitelial, alterando a manutenção da osmolaridade do estroma anterior ${ }^{(44)}$. O seu desaparecimento, por volta dos 15 dias de evolução, deve-se à recuperação do recobrimento epitelial. A vascularização da córnea é esperada e necessária, desde que controlada, nos processos envolvendo reparação cicatricial da córnea ${ }^{(45)}$; o seu padrão de apresentação foi correspondente ao observado em estudos que utilizaram outras membranas biológicas ${ }^{(5-7)}$ com um diferencial: a presença desses neovasos nos períodos mais tardios, de 60 até 100 dias de pós-operatório, o que não foi encontrado no presente trabalho. A presença de alguns neovasos em um dos animais, aos 60 dias, deve-se à permanência de 3 pontos de sutura. Nos demais animais, os pontos desprenderam-se espontaneamente por volta dos 30 dias. A mácula resultante que, por sua localização, provavelmente não interfere com a visão funcional do animal, deve-se ao próprio processo de cicatrização, no qual, mesmo ocorrendo naturalmente, produz colágeno de diâmetro e características diferentes do nativo ${ }^{(46)}$. A distribuição das 
cadeias de colágeno (IV) na membrana basal da membrana amniótica é similar à distribuição existente na conjuntiva, mas não à existente na córnea ${ }^{(47)}$.

Quanto à resposta inflamatória induzida pela enxertia da membrana fetal, uma vez que o infiltrado é formado somente por polimorfonucleares neutrófilos, não caracteriza uma resposta de rejeição do tecido implantado, apenas reação inflamatória aguda necessária para a cicatrização estromal ${ }^{(47)}$, apesar da presença do córion, que é considerado a porção mais imunogênica da membrana fetal ${ }^{(39)}$. Essa resposta inflamatória mostrou-se menor em duração e intensidade que a apresentada pela utilização da membrana amniótica xenógena de forma penetrante ${ }^{(29)}$; do peritônio homólogo ${ }^{(5)}$, no qual havia também a presença de mononucleares; e do pericárdio xenógeno $^{(4)}$ que, no $100^{\circ}$ dia de evolução, ainda se notava infiltrado inflamatório crônico discreto.

Futuras perguntas serão respondidas quando compararmos os atuais resultados com as reações encontradas quando implantadas "membrana fetal" e "membrana amniótica" alógenas e aumentando o número de animais da amostra.

Conclui-se, portanto, que o emprego da membrana fetal eqüina em ceratoplastia lamelar em cães é factível, produzindo bons resultados na reconstrução da integridade da superfície corneana.

\section{ABSTRACT}

Purpose: To evaluate the applicability of the equine fetal membrane (amniotic membrane, chorion and alantoid) as graft in lamelar keratoplasty in dogs. Methods: 9 mixed breed dogs were used, according to the ARVO statement for use of animals in ophthalmic and vision research. Superficial keratectomy was performed with a $5 \mathrm{~mm}$ trephine and a $6 \mathrm{~mm}$ diameter fragment of the fetal membrane that was sutured in place with 8-0 nylon simple interrupted stitches. Clinical examination were performed during 2, 7, 15 and 60 days and, afterwards, the animals were euthanized; the eyes were enucleated for histological study. Results: Clinically, one could observe slight corneal edema near the implant since the early phases, until the middle stage of the investigation. Neovascularization appeared progressively; its higher intensity was observed in the intermediate phase, disappearing gradually. At 60 days, one could notice a macula at the surgery site. The histological findings showed epithelialization and perfect integration of the graft to the receptor tissue at early stages; the cellular and vascular reactions were more intense in this phase. On day 15 , the vascular elements were reduced in relation to the matrix and cellular elements. At any stage, inflammatory infiltrate in the graft, as well at the site of the suture were not observed. Conclusions: The equine fetal membrane (amniotic membrane, chorion and alantoid) can be useful as graft in lamellar keratoplasty in dogs.

Keywords: Corneal transplantation/veterinary; Fetal membranes/transplantation; Animal; Dogs/surgery; Horses/surgery

\section{REFERÊNCIAS}

1. Barros PSM, Safatle AMV, Malerba TA, Burnier Junior M. The surgical repair of the cornea of the dog using pericardium as a keratoprosthesis. Braz $\mathbf{J}$ Vet Res Anim Sci 1995;32:251-5.

2. Barros PSM, Laus JL, Morales A, Ferreira AL, Safatle AMV. Reparação experimental de lesões lamelares da esclera de cães com pericárdio xenólogo conservado. Arq Bras Oftalmol 1996;59:462-6.

3. Barros PSM, Safatle AMV, Rigueiro M. Uso do pericárdio de eqüino conservado em glicerina como enxerto penetrante da córnea de cães. Estudo experimental. Braz J Vet Res Anim Sci 1997;34:138-41.

4. Barros PSM, Safatle AMV, Rigueiro M. Experimental lamellar corneal graft in dogs using preserved equine pericardium. Braz J Vet Res Anim Sci 1999; 36:304-7.

5. Garcia JA, Barros PSM., Laus JL, Ferreira AL, Safatle AMV. Implante de peritônio homólogo conservado após ceratectomia lamelar em cães. Braz J Vet Res Anim Sci 1996;33 Suppl:290-4.

6. Andrade AL, Emprego experimental da cápsula renal de eqüino (Equus caballus) conservada em glicerina, no reparo de ceratectomias superficiais em cães (Canis familiaris). Avaliação clínica e morfológica [tese]. Jaboticabal: Faculdade de Ciências Agrárias e Veterinárias - Universidade Estadual Paulista "Júlio de Mesquita Filho"; 1996.

7. Galera PD, Emprego da túnica vaginal autógena, a fresco, em ceratoplastias lamelares experimentais em cães [tese]. Jaboticabal: Faculdade de Ciências Agrárias e Veterinárias - Universidade Estadual Paulista "Júlio de Mesquita Filho"; 1999.

8. Lewin GA, Repair of a full thickness corneoscleral defect in a German shepherd dog using porcine small intestinal submucosa. J Small Anim Pract 1999;40:340-2.

9. Featherstone H, Sansom J. Intestinal submucosa repairs in two cases of feline ulcerative keratitis. Vet Rec 2000;146:136-8.

10. Laus JL. Emprego de escama de sardinha (Sardinella brasilienses) conservada em glicerina como sucedâneo de córneas no reparo de ceratectomias superficiais. Estudo experimental em cães (Canis familiaris) [tese]. Jaboticabal: Faculdade Ciências Agrárias e Veterinárias - Universidade Estadual Paulista "Júlio de Mesquita Filho"; 1994.

11. Kim TC, Tseng SC. Transplantation of preserved human amniotic membrane for surface reconstruction in severely damaged rabbit corneas. Cornea 1995; 14:473-84.

12. Tsubota K, Satake Y, Ohyama M, Toda I, Takano Y, Ono M, et al. Surgical reconstruction of the ocular surface in advanced ocular cicatricial pemphigoid and Stevens-Johnson Syndrome. Am J Ophthalmol 1996;122:38-52.

13. Tseng SC, Prabhasawat P, Barton K, Gray T, Meller D. Amniotic membrane transplantation with or without limbal allografts for corneal surface reconstruction in patients with limbal stem cell deficiency. Arch Ophthalmol 1998;166:431-41.

14. Tseng SC, Prabhasawat P, Lee SH. Amniotic membrane transplantation for conjunctival surface reconstruction. Am J Ophthalmol 1997;124:765-74.

15. Lee SH, Tseng SC. Amniotic membrane transplantation for persistent epithelial defects with ulceration. Am J Ophthalmol 1997;123:303-12.

16. Shimazaki J, Shinozaki N; Tsubota K. Transplantation of amniotic membrane and limbal autograft for patients with recurrent pterygium associated with symblepharon. Br J Ophthalmol 1998;82:235-40.

17. Shimazaki J, Yang HY, Tsubota K. Amniotic membrane transplantation for ocular surface reconstruction in patients with chemical and thermal burns. Ophthalmology 1997;104:2068-76.

18. Prabhasawat P, Barton K, Barkett G, Tseng SC. Comparison of conjunctival autografts, amniotic membrane grafts and primary closure for pterygium excision. Ophthalmology 1997;104:974-85.

19. Pires RT, Tseng SC, Prabhasawat P, Puangsricharem V, Maskin SL, Kim JC, Tan DT. Amniotic membrane transplantation for symptomatic bullous keratopathy. Arch Ophthalmol 1999;117:1291-7.

20. Kruse FE, Rohrschneider K, Vülcker HE. Multilayer amniotic membrane transplantation for reconstruction of deep corneal ulcers. Ophthalmology 1999; 106:1504-11.

21. Gomes JAP, Komagome CM, Santos N, Cunha MC, Freitas D. Membrana amniótica nas cirurgias reconstrutivas da superfície ocular nas ceratoconjuntivites cicatriciais. Arq Bras Oftalmol 1999;62:562-76.

22. Honavar SG, Bansal AK, Sangwan VS, Rao GN. Amniotic membrane transplantation for ocular surface reconstruction in Stevens-Johnson syndrome. Ophthalmology 2000;107:975-9.

23. Meller D, Pires RT, Mack RJS, Figueiredo F, Heiligenhaus A, Park WC, et al. Amniotic membrane transplantation for acute chemical or thermal burns. Ophthalmology 2000;107:980-90. 
24. Chen HJ, Pires RT, Tseng SC. Amniotic membrane transplantation for severe neurotrophic corneal ulcers. Br J Ophthalmol 2000;84:826-33.

25. Barton K, Budenz DL, Khaw PT, Tseng SCG. Amniotic membrane transplantation in glaucoma surgery. Invest Ophthalmol Vis Sci 1997;38:S473.

26. Fujishima H, Shimazaki J, Shinozaki N, Tsubota K. Trabeculectomy with the use of amniotic membrane for uncontrollable glaucoma. Ophthalmic Surg Lasers 1998;29:428-31.

27. Choi YS, Kim JY, Wee WR, Lee JH. Effect of the application of human amniotic membrane on rabbit corneal wound healing after excimer laser photorefractive keratectomy. Cornea 1998;17:389-95.

28. Koizumi N, Inatomi T, Quantock AJ, Fullwood NJ, Dota A, Kinoshita S. Amniotic membrane as a substrate for cultivating limbal corneal epithelial cells for autologous transplantation in rabbits. Cornea 2000;19:65-71.

29. Barros PSM, Garcia JA, Laus JL, Ferreira AL, Gomes TS. The use of xenologous amniotic membrane to repair canine corneal perforation created by penetrating keratectomy. Vet Ophthalmol 1998;1:119-23.

30. McManus JFA, Mowry RW. Staining methods. Histologic and histochemical. 3. ed. USA: Harper \& Row; 1960.

31. Davis JW. Skin transplantation with a review of 550 cases at The Johns Hopkins Hospital. Johns Hopkins Med J 1910;15:307.

32. DeRoth A. Plastic repair of conjunctival defects with fetal membranes. Arch Ophthalmol 1940;23:522.

33. Dua HS, Azuara-Blanco A. Aminiotic membrane transplantation. Br J Ophthalmol 1999;83:748-52.

34. Adinolfi M, Akle CA, McColl I, Fensom AH, Tansley L, Connolly P, et al. Expression of HLA antigens, beta 2 - microglobulin and enzymes by human amniotic epithelial cells. Nature 1982;295:325-7.

35. Azuara-Blanco A, Pillai CT, Dua HS. Amniotic membrane transplantation for ocular surface reconstruction. Br J Ophthalmol 1999;83:399-402.
36. Houlihan JM, Biro PA, Harper HM, Jenkinson HJ, Holmes CH. The human amnion is a site of MHC class Ib expression: evidence for the expression of HLA-E and HLA-G. J Immunol 1995;154:5665-74.

37. Tseng SC, Li DQ, Ma X. Suppression of transforming growth factor -beta isoforms, TGF-beta receptor type II, and myofibroblast differentiation in cultured human corneal and limbal fibroblasts by amniotic membrane matrix. J Cell Physiol 1999;179:325-35.

38. Fukuda K, Chikama T, Nakamura M, Nishida T. Differential distribution of subchains of the basement membrane components type IV collagen and laminin among the amniotic membrane, cornea and conjunctiva. Cornea 1999;18:73-9.

39. Trelford JD, Trelford-Sauder M. The amnion in surgery, past and present. Am J Obstet Gynecol 1979;134:833-45.

40. Li DQ, Tseng SC. Three patterns of cytokine expression potentially involved in epithelial-fibroblast interactions of human ocular surface. J Cell Physiol 1995;163:61-79.

41. Kurpakus MA, Stock EL, Jones JC. The role of the basement membrane in differential expression of keratin proteins in epithelial cells. Dev Biol 1992; 150:243-55.

42. Power WJ, Neves RA. Anatomia e fisiologia da córnea. In: Belfort JrR, KaraJosé N. Córnea - Clínica Cirúrgica. São Paulo: Roca; 1997. p.3-15.

43. Kern TJ. Ulcerative keratitis. Vet Clin North Am Small Anim Pract 1990; 20:643-66.

44. Krachmer JH, Mannis MJ, Holland SJ, Palay DA. Fundamentals of cornea and external disease. In: Krachmer JH, Mannis MJ, Holland SJ, Palay DA Cornea. [Monograph on CD-ROM]. St. Louis: Mosby Yearbook; 1998.

45. Peruccio C. Diagnosi e trattamento delle lesioni corneali. Sci Vet 1983;4:3-8.

46. Matsuda H, Smelser GK. Electron microscopy of corneal wound healing. Exp Eye Res 1973;16:427-42

47. Hayashi S, Belfort JrR. Imunologia da córnea. In: Belfort JrR, Kara-José N. Córnea - Clínica Cirúrgica. São Paulo: Roca; 1997. p.52-64.

\title{
Simpósio Internacional do Hospital Offalmológico de Sorocaba
}

\author{
08 e 09 de Novembro de 2002 \\ SOROCABA - SP
}

Auditório do Hospital Oftalmológico de Sorocaba

INFORMAçÕES: tel/fax: (15) $212-9000$ - r. 9077 c/ Dra. Luciene Barbosa de Souza

E-mail: ceo@hosbos.com.br 